\title{
Sex- and age-specific immunomodulatory effects of dietary soya protein isolate and isoflavones in rats
}

\author{
Stephen M. Cornish ${ }^{1}$, Carla M. Wood ${ }^{1}$, Mary R. L'Abbé ${ }^{1}$, G. Sarwar Gilani ${ }^{1}$, Gerard M. Cooke ${ }^{2}$, \\ Ivan H. Curran ${ }^{2}$ and Chao Wu Xiao ${ }^{1,3 *}$ \\ ${ }^{1}$ Nutrition Research Division, Food Directorate, Health Products and Food Branch, Health Canada, Ottawa, ON, Canada \\ K1A $O K 9$ \\ ${ }^{2}$ Toxicology Research Division, Food Directorate, Health Products and Food Branch, Health Canada, Ottawa, ON, Canada \\ K1A OK9 \\ ${ }^{3}$ Department of Cellular and Molecular Medicine, Faculty of Medicine, University of Ottawa, Ottawa, ON, Canada
}

(Received 1 June 2010 - Revised 27 January 2011 - Accepted 27 January 2011 - First published online 27 April 2011)

\section{Abstract}

The present study examined, using rats as a model, the effects of sex and age of exposure to dietary soya components on serum total and soya-specific antibody content. In Expt 1, Sprague-Dawley rats at $50 \mathrm{~d}$ of age were fed diets containing $20 \%$ casein or $20 \%$ alcohol-washed soya protein isolate (SPI) with or without supplemental isoflavones (ISF, $250 \mathrm{mg} / \mathrm{kg}$ diet) for 70,190 or $310 \mathrm{~d}$. The offspring were fed the same diets as their parents. In Expt 2, juvenile Sprague-Dawley rats at $30 \mathrm{~d}$ of age were fed diets containing $20 \%$ casein with or without supplemental ISF $(50 \mathrm{mg} / \mathrm{kg}$ diet) or increasing amounts of alcohol-washed SPI (5, 10 or 20\%) for 90 d. Exposure of rats to dietary SPI before the age of $28 \mathrm{~d}$ increased serum total IgA and IgM, and induced the production of SPI-specific IgA, IgG, IgM and IgE antibodies. Feeding of juvenile or adult rats with SPI elevated serum total IgA in females, while the opposite occurred in males, and markedly stimulated the production of SPI-specific IgM in females and IgG in males. Our data suggest that the effects of soya proteins and ISF on the production of serum total and SPI-specific antibodies appear to be sex dependent and also related to the age of exposure to soya in rats. However, the physiological significance of these immune responses remains to be determined.

Key words: Soya protein isolate: Isoflavones: Soya-specific antibodies: Immunomodulating effects: Rats

Consumption of soya proteins and isoflavones (ISF) has been associated with many health benefits ${ }^{(1,2)}$. However, soyabeans have been listed as one of the most significant sources of food allergens ${ }^{(3)}$, and contain diabetogenic agents and autoimmunogens ${ }^{(4)}$, inducing autoimmune diseases such as type 1 diabetes in BioBreeding rats and non-obese diabetic mice ${ }^{(5)}$.

Sex hormones such as oestradiol play an important role in mediating immune responses ${ }^{(6,7)}$. Soya ISF mainly consist of genistein, daidzein and glycitein, and have oestrogenic and anti-oestrogenic effects because of their structural similarity to that of mammalian oestradiol ${ }^{(8,9)}$. Many post-menopausal women choose to consume soya products or ISF supplements as an alternative to hormone replacement therapy ${ }^{(10)}$. Meanwhile, a large number of infants take high amounts of ISF from soya-based formulas. However, existing knowledge on the effects of soya proteins and ISF ingested from food sources on immune functions of different age groups such as infants, youths and adults as well as the impact of maternal intake during pregnancy and lactation on their offspring is quite limited. The purpose of the present study was to examine the effects of sex and age of exposure to dietary soya components on the content of serum total and soya proteinspecific antibodies using rats as a model.

\section{Materials and methods}

\section{Chemicals and reagents}

Alcohol-washed soya protein isolate (SPI, Pro Fam 930) and Novasoya ISF concentrate were purchased from Archer Daniels Midland Company (Decatur, IL, USA). Casein protein ( $90 \%$ protein) was from ICN (Cleveland, OH, USA). Rat IgA, IgE, IgG and IgM ELISA quantification kits were purchased from Bethyl Laboratories, Inc. (Montgomery, TX, USA).

Abbreviations: $\mathrm{F}_{1}$, offspring generation; ISF, isoflavone; SPI, soya protein isolate.

*Corresponding author: C. W. Xiao, fax +1 613941 6182, email chaowu_xiao@hc-sc.gc.ca 


\section{Animals and diets}

Animal experimental protocols were approved by the Health Canada Animal Care Committee, and all animal handling and care followed the guidelines of the Canadian Council for Animal Care. Rats were kept in an environmentally controlled room with a $12 \mathrm{~h}$ light $-12 \mathrm{~h}$ dark cycle. At the end of the study, rats were killed by exsanguination through cardiac puncture under general anaesthesia with isoflurane. Sera were collected, immediately frozen in liquid $\mathrm{N}_{2}$ and stored at $-80^{\circ} \mathrm{C}$ until analysis.

In Expt 1, pubertal Sprague-Dawley rats (Charles River, St Constant, PQ, Canada) at $50 \mathrm{~d}$ of age were randomly allocated into three groups (twenty-three males and twenty-three females per group) as the parental generation. Rats were given free access to tap water and one of the three diets. The specifications of the AIN93G diet ${ }^{(11)}$ were followed in the preparation of all diets, except that in diets 2 and 3 , $20 \%$ casein was replaced by $20 \%$ alcohol-washed SPI. Additionally, diet 3 was supplemented with ISF $(250 \mathrm{mg} / \mathrm{kg}$ diet). After being fed for 70,190 or $310 \mathrm{~d}$, six males and six females from each diet group were randomly selected and killed, and sera were collected and stored as described earlier. At $120 \mathrm{~d}$ of age, five males and five females from the same diet group were randomly selected and housed together for mating to produce offspring generation $\left(F_{1}\right)$. The $F_{1}$ pups were weaned at $21 \mathrm{~d}$ of age, and twenty-four pups of each sex from each diet group were randomly selected and fed the same diet as their parents throughout life. At 28, 70, 120 and $240 \mathrm{~d}$ of age, six males and six females from each diet group were randomly selected and killed, and sera were collected as stated earlier.
In Expt 2, juvenile Sprague-Dawley rats at $30 \mathrm{~d}$ of age (six males and six females per group) were fed diets containing $20 \%$ casein in the absence or presence of $50 \mathrm{mg} / \mathrm{kg}$ diet of supplemental ISF or increasing amounts of alcohol-washed SPI $(5,10$, or $20 \%$ ) with decreased amounts of casein (15, 10 or $0 \%$ ) for $90 \mathrm{~d}$. At the end of the feeding period, rats were killed and sera were collected. The actual total ISF including genistein, daidzein and glycitein were measured as aglycones by Waters HPLC linear gradient with UV detection monitored at $254 \mathrm{~nm}^{(12)}$. Casein was used in the control diets in consideration of the popular consumption of dairy products in Western diets and being one of the major sources of proteins in infant formulas.

\section{Measurement of serum total and soya protein-specific antibodies}

Serum IgA, IgE, IgG and IgM concentrations were measured using commercial rat ELISA quantification kits according to the manufacturer's instructions. The concentrations of $\mathrm{Ig}$ were calculated against the standard.

For the measurement of soya protein-specific antibodies, diluted serum samples (1:10 for IgA, IgE, and IgG and 1:50 for IgM) were added into alcohol-washed SPI (10 mg/1)coated plates. After incubation with either horseradish peroxidase-conjugated goat anti-rat IgA (1:80 000), sheep anti-rat IgE (1:1000), rabbit anti-rat IgG (1:50000) or goat anti-rat IgM (1:30000) antibodies, the plates were added with horseradish peroxidase substrate. The absorbance was read at $650 \mathrm{~nm}$. The relative content of serum soya protein-specific Ig was expressed as the optical density at $650 \mathrm{~nm}$ after subtraction of the respective background. The average backgrounds for
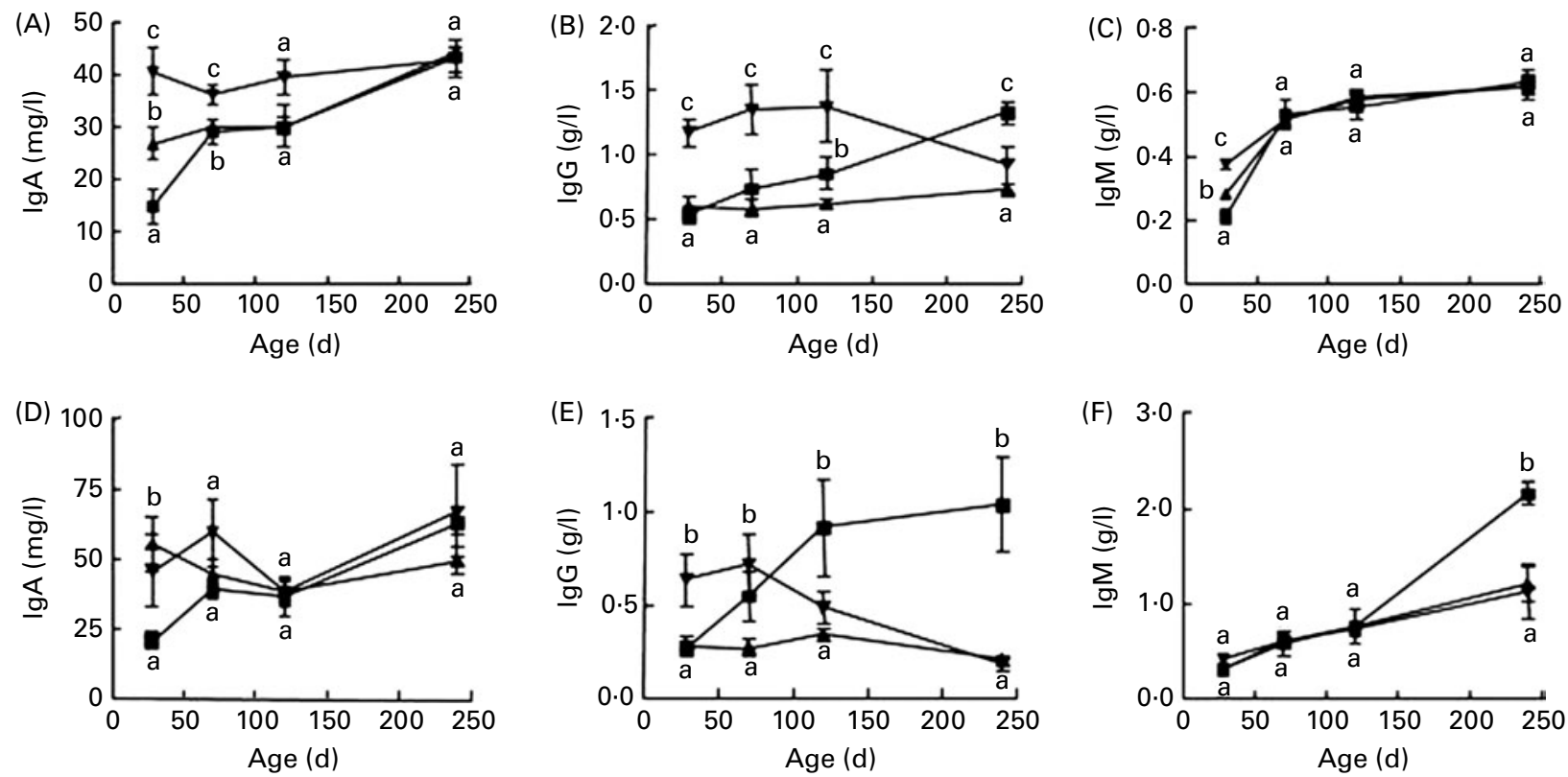

Fig. 1. Serum total $\lg A$, IgG and $\lg M$ contents in $F_{1}$ female $(A-C)$ and male $(D-F)$ rats fed diets containing either casein ( --$)$ or alcohol-washed soya protein isolate (SPI, _- ) in the absence or presence of supplemental isoflavones (ISF, $250 \mathrm{mg} / \mathrm{kg}$ diet) and necropsied at $28,70,120$ or $240 \mathrm{~d}$ of age. Values are means, with their standard errors represented by vertical bars $(n 6)$. ${ }^{a, b, c}$ Mean values with unlike letters were significantly different at the same time point $(P<0.05) . \rightarrow$, SPI + ISF. 
IgA, IgG, IgM and IgE were 0.03, 0.05, 0.05 and 0.04, respectively. The inter-assay CV for $\operatorname{IgA}, \operatorname{IgG}, \operatorname{Ig} M$ and $\operatorname{IgE}$ were $4 \cdot 2$, $6 \cdot 5,5.3$ and $4.8 \%$, respectively.

\section{Statistical analyses}

Results are expressed as means with their standard errors. Serum SPI-specific IgA, IgG, IgM and IgE contents were transformed to logarithms to eliminate heterogeneity of variance. Age or sex and dietary effects on serum total or SPI-specific IgA, IgG, IgM and IgE were analysed using one-way or twoway ANOVA. Differences between individual means were determined by Fisher's least significant difference test. A probability of $P<0.05$ was considered to be significant. All data were analysed using STATISTICA version 6.1 (StatSoft, Inc., Tulsa, OK, USA). The sample size was $n 6$.

\section{Results}

\section{Total isoflavones in diets}

In Expt 1, the actual total ISF in $20 \%$ casein, $20 \%$ SPI or $20 \%$ SPI + ISF were $0,31.7$ and $235.6 \mathrm{mg} / \mathrm{kg}$ diet, respectively. In Expt 2, the actual total ISF in $20 \%$ casein, $20 \%$ casein + ISF, $5 \%$ SPI $+15 \%$ casein, $10 \%$ SPI $+10 \%$ casein or $20 \%$ SPI were $0,42.8,7.9,15.9$ or $31.7 \mathrm{mg} / \mathrm{kg}$ diet, respectively.

(A)



(B)

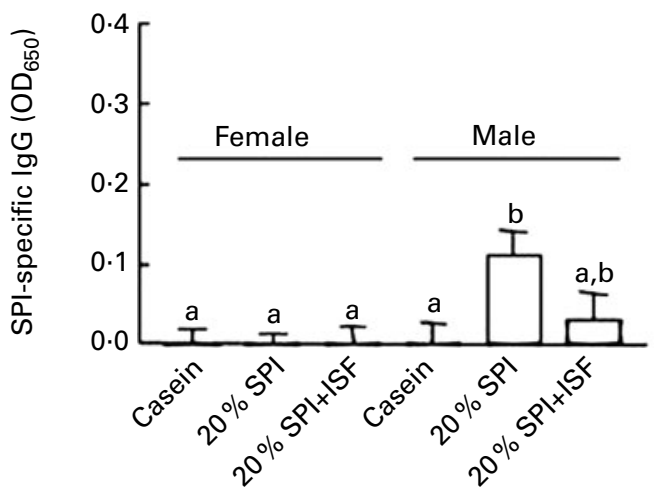

\section{Total IgA, IgE, IgG and IgM content}

Serum total IgA was significantly increased in parental generation female rats at the ages of $240 \mathrm{~d}$ (90.4 (SEM 10.6) $v .51 \cdot 3$ (sem 2.9) $\mathrm{mg} / 1, P<0.01$ ) and $360 \mathrm{~d}(94.5$ (sem 7.9) $v .72 .5$ (sem $4 \cdot 1) \mathrm{mg} / \mathrm{l}, P<0.05$ ), and decreased in male rats at the age of $360 \mathrm{~d}(91.2$ (SEM 10.6) $v$. $129 \cdot 0$ (sem 13.8) mg/l, $P<0.05$ ) by dietary SPI compared with a casein-based diet. Addition of ISF to the SPI diet elevated IgA concentration in female rats at $120 \mathrm{~d}$ of age (61.7 (SEM 5.8) v. 46.0 (SEM 6.3) $\mathrm{mg} / \mathrm{l}, P<0.05)$ and further decreased IgA concentration in male rats at $360 \mathrm{~d}$ of age $(62.5$ (sem 3.3) v. 91.2 (SEM 10.6) $\mathrm{mg} / \mathrm{l}, P<0 \cdot 01$ ) compared with rats consuming SPI diets.

In $\mathrm{F}_{1}$, female rats fed the diet containing SPI alone had significantly higher IgA and IgM content at $28 \mathrm{~d}$ of age (Fig. 1(A) and $(\mathrm{C})$ ) and lower IgG level at $240 \mathrm{~d}$ of age (Fig. 1(B)) than those fed the casein-based diet $(P<0 \cdot 05)$. Addition of ISF to the SPI-based diet further increased the serum IgA and IgM in female rats at $28 \mathrm{~d}$ of age (Fig. 1(A) and (C), $P<0.01$ ), and markedly increased IgG content in rats at 28, 70 and $120 \mathrm{~d}$ of age (Fig. 1(B)) compared with casein and SPI alone. Male rats fed SPI-based diets had higher IgA at $28 \mathrm{~d}$ of age (Fig. 1(D)) and lower IgM at $240 \mathrm{~d}$ of age (Fig. 1(F)). Supplemental ISF increased IgG at $28 \mathrm{~d}$ of age. Male rats fed the soya-based diet had much lower total IgG at $240 \mathrm{~d}$ of age than those fed the casein-based diet (Fig. 1(E)).

(C)

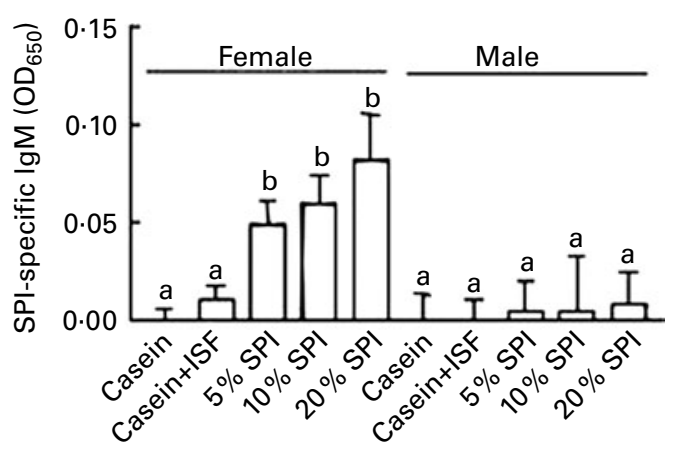

(D)



Fig. 2. Differential effects of soya protein isolate (SPI) and isoflavones (ISF) on SPI-specific IgM and IgG in male and female rats fed diets containing either casein or alcohol-washed SPI with or without supplemental ISF $(250 \mathrm{mg} / \mathrm{kg}$ diet) in Expt 1 (A and B) or diets containing casein in the absence or presence of $50 \mathrm{mg} / \mathrm{kg}$ diet of supplemental ISF or increasing amounts of alcohol-washed SPI (5, 10, or $20 \%)$ in Expt 2 (C and D). Values are means, with their standard errors represented by vertical bars $(n 6) .{ }^{a, b}$ Mean values with unlike letters were significantly different $(P<0.05)$. OD, optical density. 
Soya protein isolate-specific antibodies in rats exposed to dietary soya before $28 d$ of age or after $30 d$ of age

In both Expt 1 and 2, the SPI diet markedly elevated SPIspecific IgM in female rats and IgG in male rats compared with the casein-based diet at $120 \mathrm{~d}$ of age $(P<0.05$; Fig. 2$)$. In $\mathrm{F}_{1}$ female rats fed $20 \%$ SPI diets at day 28 , all SPI-specific antibodies including IgA, IgG, IgE and IgM increased; addition of ISF to the SPI diet had no significant effect on IgA, IgM and IgE, and inhibited the stimulatory effect of SPI on IgG (data not shown).

\section{Discussion}

The present study showed that exposure to soya-derived ISF at early life significantly increased serum total IgA, IgM and IgG levels in the weanling female rats compared with other diets but had no significant effect on IgA or IgM levels in male rats. This suggests that ISF may have sexassociated immunomodulatory functions. Similar effects have also been observed in an in vitro study, showing that $17 \beta$-oestradiol or daidzein increased $\operatorname{IgM}$ and $\operatorname{IgE}$ production, while genistein reduced IgM and increased IgE concentrations in cultured mouse splenocytes ${ }^{(13)}$. Although the mechanism(s) by which soya ISF affects the serum total Ig content remains unclear, existing evidence suggests a possible role of soya ISF in modulating the number of antibody-producing cells. For example, ingestion of daidzein increased spleen IgM-producing cells in mice ${ }^{(14)}$. Feeding the female rats with genistein markedly increased splenic B-cells in their offspring of both sexes and elevated IgM antibody-forming cells only in female but not in male offspring ${ }^{(15)}$. The present study used soya-derived ISF rather than pure isolated genistein or daidzein, which may better represent the situation of human intake of soya foods, soyabased infant formulas or ISF supplements.

Circulating IgG and IgM play important roles in antiinfection through engaging the phagocytic system and activating the complement system, whereas IgA may compete with IgG and IgM for the same antigen and block complement activation. Additionally, serum IgA inhibits phagocytosis, chemotaxis and antibody-dependent cellular cytotoxicity $^{(16)}$. Therefore, changes in serum Ig isotypes by dietary soya ISF and proteins may affect the immune function of rats.

The oestrogenic effects and selective binding of soya ISF to oestrogen receptors may play a key role in the sex-dependent modulation of antibody production. The binding affinity of soya ISF to oestrogen receptor $\beta$ is twenty times greater than that to oestrogen receptor $\alpha^{(17)}$, which is very different from the endogenous oestradiol. The type of oestrogen receptors (i.e. $\alpha$ or $\beta$ ) bound is believed to have a profound impact on humoral immunity ${ }^{(15)}$. Therefore, the intake of soya ISF supplements may alter the humoral immunity in postmenopausal women.

The present study also demonstrated that SPI-specific antibodies (IgA, IgG, IgM and IgE) were present in sera of $F_{1}$ female rats fed soya diets at $28 \mathrm{~d}$ of age for 1 week before necropsy. These antibodies, especially IgA, IgG and IgE, might have been produced in response to the dietary source of soya proteins rather than transferred from the maternal source, because only SPI-specific IgM was detected in their dams. This suggests that gastrointestinal tracts in the newly weaned rats may have not been well developed, and soya protein fragments or peptides can be absorbed into the circulation and thereby stimulating the specific immune response.

In summary, the present study has demonstrated that dietary soya ISF significantly affect the content of serum total antibodies in a sex- and age-dependent manner. Furthermore, exposure to dietary soya proteins at early life $(<28 \mathrm{~d}$ of age) induces production of SPI-specific antibodies, suggesting that those rats may be vulnerable to the development of soya allergy or autoimmune diseases. Whether the consumption of soya foods has similar effects in humans warrants further investigation.

\section{Acknowledgements}

The present study was funded by Health Canada. S. M. C. was a recipient of Health Canada Postdoctoral Fellowship. None of the authors had any conflicts of interest. C. W. X. contributed to the experimental design, animal studies and data analysis. S. M. C. and C. M. W. conducted the sample analyses. G. S. G. analysed the dietary isoflavone content. M. R. L. A., G. M. C. and I. H. C. contributed to the design and animal study of Expt 1.

\section{References}

1. Hermansen K, Sondergaard M, Hoie L, et al. (2001) Beneficial effects of a soy-based dietary supplement on lipid levels and cardiovascular risk markers in type 2 diabetic subjects. Diabetes Care 24, 228-233.

2. Xiao CW (2008) Health effects of soy protein and isoflavones in humans. J Nutr 138, 1244S-1249S

3. Food and Agriculture Organization of the United Nations (1995) Report of the FAO Technical Consultation on Food Allergies. Rome: Food and Agriculture Organization of the United Nations.

4. Hoorfar J, Scott FW \& Cloutier HE (1991) Dietary plant materials and development of diabetes in the BB rat. $J$ Nutr 121, 908-916.

5. Scott FW (1996) Food-induced type 1 diabetes in the BB rat. Diabetes Metab Rev 12, 341-359.

6. Cook IF (2008) Sexual dimorphism of humoral immunity with human vaccines. Vaccine 26, 3551-3555.

7. Kovacs EJ, Messingham KA \& Gregory MS (2002) Estrogen regulation of immune responses after injury. Mol Cell Endocrinol 193, 129-135.

8. Whitten PL \& Patisaul HB (2001) Cross-species and interassay comparisons of phytoestrogen action. Environ Health Perspect 109, Suppl. 1, 5-20.

9. Lephart ED, Setchell KD, Handa RJ, et al. (2004) Behavioral effects of endocrine-disrupting substances: phytoestrogens. ILAR J 45, 443-454.

10. Hutchins AM, McIver IE \& Johnston CS (2005) Hypertensive crisis associated with high dose soy isoflavone supplementation in a post-menopausal woman: a case report [ISRCTN98074661]. BMC Womens Health 5, 9. 
11. Reeves PG, Nielsen FH \& Fahey GC Jr (1993) AIN-93 purified diets for laboratory rodents: final report of the American Institute of Nutrition ad boc writing committee on the reformulation of the AIN-76A rodent diet. J Nutr $\mathbf{1 2 3}$, 1939-1951.

12. Wang $\mathrm{HJ} \&$ Murphy $\mathrm{P}$ (1994) Isoflavone content in commercial soybean foods. J Agric Food Chem 42, 1666-1673.

13. Han D, Denison MS, Tachibana H, et al. (2002) Effects of estrogenic compounds on immunoglobulin production by mouse splenocytes. Biol Pharm Bull 25, 1263-1267.

14. Zhang R, Li Y \& Wang W (1997) Enhancement of immune function in mice fed high doses of soy daidzein. Nutr Cancer 29, 24-28.
15. Guo TL, White KL, Brown RD, et al. (2002) Genistein modulates splenic natural killer cell activity, antibody-forming cell response, and phenotypic marker expression in $\mathrm{F}(0)$ and F(1) generations of Sprague-Dawley rats. Toxicol Appl Pharmacol 181, 219-227.

16. Wolf HM, Fischer MB, Puhringer H, et al. (1994) Human serum IgA downregulates the release of inflammatory cytokines (tumor necrosis factor-alpha, interleukin-6) in human monocytes. Blood 83, 1278-1288.

17. Kostelac D, Rechkemmer G \& Briviba K (2003) Phytoestrogens modulate binding response of estrogen receptors alpha and beta to the estrogen response element. J Agric Food Chem 51, 7632-7635. 